\title{
Rancangan Aplikasi Seleksi Atlet Taekwondo Menggunakan Framework Codeigniter dengan Metode TOPSIS
}

\author{
Tirta Dwi Budiarto \\ Teknik Informatika, Universitas Trilogi \\ Jalan Kampus Trilogi / STEKPI No.1, Kalibata, Jakarta Selatan 12760 \\ e-mail: tirtabudiarto@trilogi.ac.id
}

\begin{abstract}
Abstrak
Taekwondo merupakan salah satu cabang olahraga di bidang bela diri yang berasal dari Negara Korea. Seseorang yang ingin mengikuti pertandingan taekwondo biasanya harus mengikuti seleksi yang diadakan. Proses seleksi dalam menentukan seleksi atlet taekwondo masih mengalami kendala. Dilapangan masih ditemukan kendala dalam pemilihan atlet yang diakibatkan oleh sistem yang masih menggunakan cara manual atau konvensional. Selain itu pengambilan keputusan tidak dapat melihat kriteria - kriteria dalam prestasi secara bersama sama. Adapun kekurangan dalam proses seleksi atlet yaitu adanya kecurangan penyeleksian atlet binaan, serta lambatnya proses penentuan penilaian penyeleksian atlet binaan. Untuk menyelesaikan masalah tersebut maka diterapkan sistem pendukung keputusan (SPK) yang dirancang untuk meningkatkan keefektivitas dalam melakukan pengambilan keputusan serta menghasilkan keputusan yang optimal. Dalam sistem pendukung keputusan ini metode yang dapat digunakan adalah metode TOPSIS. Kriteria penilaian yang digunakan sebagai acuan penilaian yaitu teknik, taktik, mental, fisik, umur, refleks dan fleksibilitas. Kriteria tersebut akan menjadi acuan penilaian untuk medapatkan nilai akhir.
\end{abstract}

Kata Kunci: Atlet, Metode TOPSIS, Sistem Pendukung Keputusan, Seleksi, Taekwondo

\begin{abstract}
Taekwondo is one of the sports in martial arts originating from Korea. Someone who wants to take part in a taekwondo competition usually has to take part in the selection held. The selection process in determining the selection of taekwondo athletes is still having problems. In the field there are still obstacles in the selection of athletes caused by systems that still use manual or conventional methods. Apart from that decision making cannot see the criteria in achievement together. The shortcomings in the athlete selection process are the existence of fraudulent selection of trained athletes, as well as the slow process of determining the assessment of selected athletes. To solve the problem, a decision support system (DSS) is designed to increase the effectiveness of decision making and produce optimal decisions. In this decision support system the method that can be used is the TOPSIS method. Assessment criteria used as a reference for assessment are technique, tactics, mental, physical, age, reflexes and flexibility. The criteria will be a reference for obtaining the final score.
\end{abstract}

Keywords: Athletes, Decision Support System, Selection, Taekwondo, TOPSIS Method

\section{Pendahuluan}

Seorang atlet taekwondo harus meningkatkan potensi dirinya dengan latihan keras dan sikap yang disiplin. Pertandingan dan kompetisi sering diadakan, untuk melihat potensi yang dimiliki atlet tersebut. Pertandingan nasional menjadi acuan para atlet untuk meningkatkan potensi dirinya ke level nasional. Sehingga para atlet menjadi lebih giat untuk berlatih dan bersungguh-sungguh dalam setiap sesi latihan agar menjadi sang juara.

Seseorang yang ingin menjadi atlet untuk pertandingan harus mengikti seleksi seleksi yang ada. Seleksi pertandingan yang dapat diikuti tersebut dibagi atas dua (2) kategori yaitu bertarung (Kyourugi) dan keindahan gerakan (Poomsae). Proses seleksi atlet biasanya berdasarkan laporan prestasi atlet dari pelatih khususnya pada atlet binaan bidang prestasi. Pihak club 
pusat akan menerima laporan serta melakukan pengecekan kelengkapan data, jika data tersebut disetujui maka atlet akan mengikuti pertandingan kategori prestasi tersebut. Namun, sering terjadi kecurangan dari proses seleksi tersebut seperti kecurangan dalam penyeleksian atlet binaan serta lambatnya proses penentuan nilai atlet binaan. Selama ini belum ada sistem yang mempermudah pelaksanaan seleksi yang bertujuan untuk menghindari kecurangan - kecurangan yang terjadi.

Sistem pendukung keputusan merupakan salah metode yang banyak digunakan untuk menyelesaikan pengambilan keputusan secara praktis yang memiliki konsep dimana alternatif yang terpilih merupakan alternatif terbaik yang memiliki jarak terpendek dari solusi ideal positif dan jarak terjauh dari solusi ideal negatif(Riandari, Hasugian, Taufik, Informatika, \& Utara, 2017). Aplikasi yang dikembangkan memakai bahasa pemrograman dengan konsep codeigniter. Hasil dari pengujian berupa peringkat berdasarkan perhitungan dari nilai hasil seleksi atlet yang telah dilakukan.

Penilaian menggunakan metode TOPSIS akan lebih tepat karena didasarkan pada nilai kriteria dan bobot yang sudah ditentukan sehingga akan mendapatkan hasil yang lebih akurat(Muzakkir, 2017). sistem penunjang keputusan yang dapat menentukan sebuah keputusan yang diambil. Sistem pendukung keputusan ini membantu melakukan penilaian setiap calon atlet taekwondo yang mengikuti penyeleksian guna mengikuti kejuaraan taekwondo. Hal ini berguna untuk memudahkan pengambilan keputusan yang terkait dengan masalah penyeleksian kejuaraan. Peneliti mencoba membantu permasalahan tersebut di atas dengan membuatkan suatu sistem pendukung keputusan menggunakan Bahasa Pemrograman HTML dengan Database MySQL.

Metode TOPSIS digunakan karena konsepnya sederhana dan mudah dipahami serta komputasi yang efisien(Widiyanto, Tri Ardy; Erliana, 2016). Aplikasi dibuat mampu mengolah data input dalam bentuk data, kriteria data, data alternatif dan kriteria pembobotan data. Memberikan bobot nilai dan kriteria mempengaruhi urutan prioritas karyawan yang dipilih. Selain itu, Sistem Pendukung Keputusan bersifat dinamik, sehingga perubahan yang terjadi pada data dapat dengan cepat diperhitungkan dan prioritas perhitungan data yang diproses dapat segera tersedia(Ma'ruf, 2016).

Perancangan aplikasi seleksi atlet taekwondo dengan konsep Model-ViewController (MVC) menggunakan pemrograman PHP Framework Codeigniter Versi 3.1.9. penggunaan konsep MVC memberikan kemudahan dalam melakukan pemrograman dan untuk mengetahui letak kesalahan yang terjadi selama program berlangsung.

Framework Codeigniter terbagi atas Model yang berguna untuk menyimpan database di dalam aplikasi sehingga ketika database dipanggil akan dapat dieksekusi oleh aplikasi. View untuk membuat bagian user interface untuk menghubungkan interaksi antara admin dengan system. Terakhir Controller yang menjadi acuan agar fungsi yang terdapat di user interface dapat berjalan sesuai dengan inputan yang dilakukan oleh pengguna.

\section{Metode Penelitian}

Pada tahapan pertama dalam penelitian ini akan dilakukan pengumpulan data yang bertujuan untuk memperoleh sejumlah informasi kriteria yang digunakan dalam seleksi taekwondo dengan mengobservasi secara langsung. Pada tahapan keduan akan dilakukan analisis mengenai kebutuhan aplikasi yang bertujuan untuk menentukan fungsi dari setiap menu pada aplikasi. Setelah melakukan analisis dilanjutkan dengan tahapan perancangan. Tahapan ini akan melakukan perancangan dari aplikasi, dimulai dari pembuatan Entity Relationship Diagram (ERD) dan Usecase Diagram. Tahapan terahir dalam penelitian ini adalah mengimplemetasi dengan mendistribusikan data pada aplikasi seleksi atlet. Selanjutnya akan dilakukan pengujian sistem yang terlah diimplementasikan yang berguna untuk mengetahui fungsi yang terdapat dalam aplikasi dapat berjalan dengan baik sesuai dengan perintah yang ada. Sebelum memulai perhitungan ditetapkan sebuah data baik data alternatif, kriteria serta nilai alternatif. Data alternatif berguna sebagai nama dari data atlet yang mengikuti seleksi. Pada data kriteria berisi acuan - acuan atau kriteria yang ada pada tahapan seleksi. Dan terakhir pada data nilai alternatif berisi bobot pada masing - masing kriteria. Pemberian 
nilai biasanya dibuatkan rentang dengan keterangan khusus tergantung studi kasus.

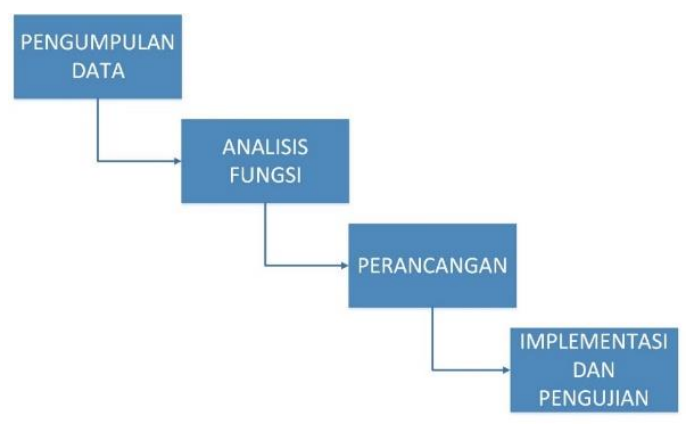

Gambar 1. Tahapan Perancangan Program

\section{Hasil dan Pembahasan}

Pada bagian ini berisi analisa, hasil serta pembahasan dari topik penelitian, yang bisa di buat terlebih dahulu metodologi penelitian. Bagian ini juga merepresentasikan penjelasan yang berupa penjelasan, gambar, tabel dan lainnya. Pembuatan program rancangan sistem ini menggunakan sebuah perangkat keras (hardware) dan perangkat lunak (software). Pada sistem ini daftar atlet yang bisa disesuaikan dengan kebutuhan sekaligus daftar kriteria - kriteria yg digunakan dalam pelaksanaan seleksi atlet. Sistem ini membutuhkan sebuah koneksi internet untuk menjalankannya. Rancangan sistem ini berupa sebuah web server.

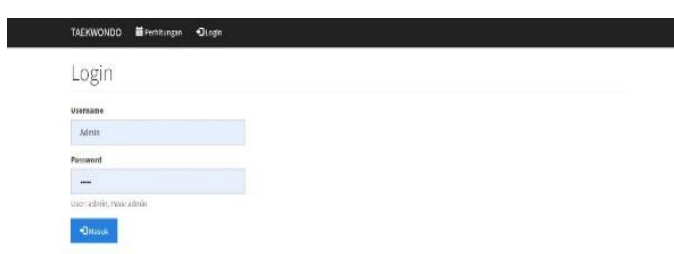

Gambar 2. Tampilan Halaman Login

Pada tampilan awal program, terdapat 2 action button yaitu perhitugan serta menu login. Gambar 2 menampilkan design dari menu login yang terdapat 2 text bar dan 1 action button. User hanya menginputkan username serta password untuk dapat melanjutkan ke halaman utama sistem. Apabila terjadi kesalahan dalam memasukan username dan password maka sistem akan menampilkan pesan "salah kombinasi username dan password" dan tetap berada di halaman login.

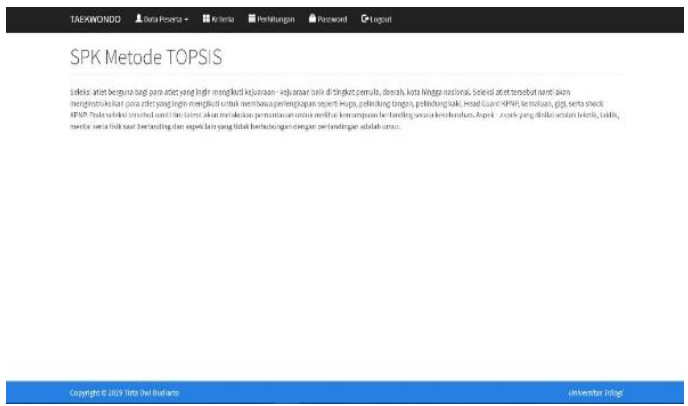

Gambar 3. Tampilan Halaman Utama

Gambar 3 menampilkan seluruh menu utama yang terdapat pada sistem pendukung keputusan. Halaman ini berisi menut - menu yang digunakan untuk menginputkan serta melakukan pengecekan data - data yang diinputkan. Halaman utama terdiri atas menu data peserta yang terdapat 2 action button yaitu data peserta dan nilai bobot peserta, menu kriteria, menu perhitungan, menu password dan menu logout

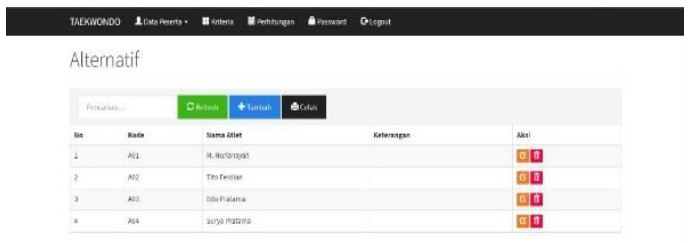

Gambar 4. Halaman Menu Data Peserta

Gambar 4 menunjukan tampilan halaman menu data peserta yang berfungsi untuk memasukan data - data peserta yang ingin mengikuti seleksi atlet taekwondo.

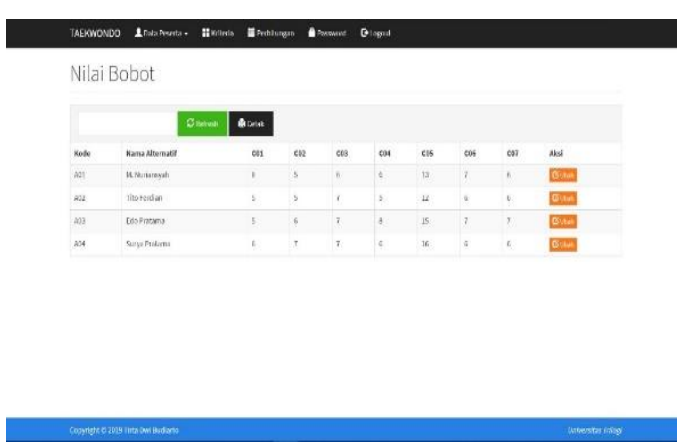

Gambar 5. Halaman Menu Nilai Peserta 
Pada gambar 5 merupakan halaman yang berisi nilai dari atlet seleksi taekwondo digunakan untuk menginputkan nilai - nilai pada saat seleksi yang dilakukan.

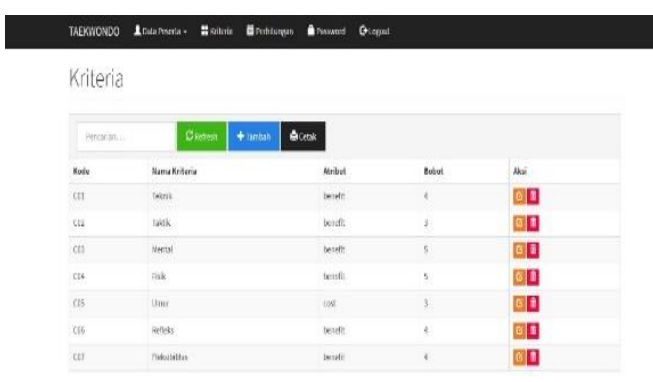

Gambar 6. Halaman Menu Kriteria

Gambar 6 menunjukan tampilan menu kriteria yang berguna untuk menginputkan data - data kriteria yang digunakan dalam penentuan nilai akhir yang mengacu pada bobot nilai dan atribut nilai.

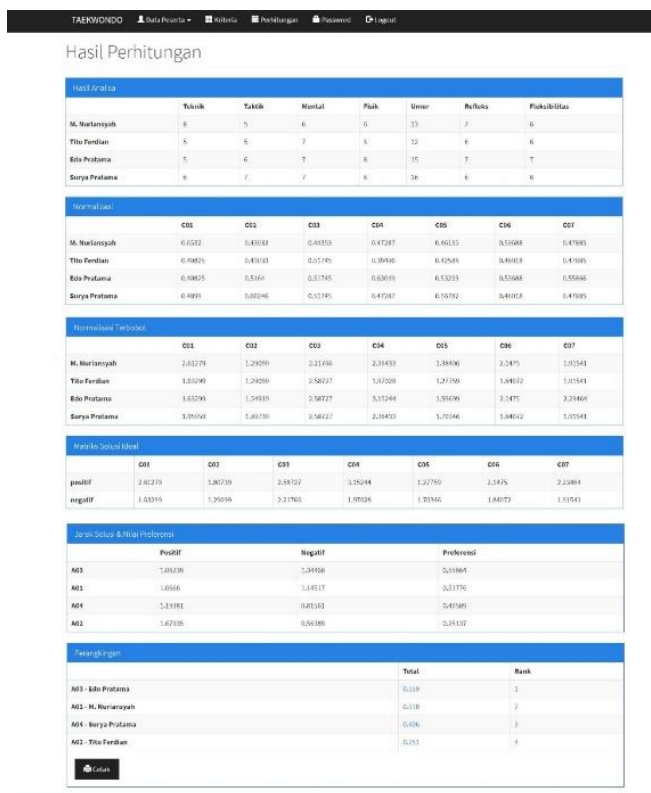

Gambar 7. Halaman Menu Perhitungan

Gambar 7 menampilkan tampilan menu perhitungan yang dilakukan oleh sistem. Perhitungan dilakukan berdasarkan penginputan nilai yang didapatkan pesert atlet taekwondo selama proses seleksi berlangsung yang mengacu pada kriteria kriteria yang telah ditetapkan. Hasil perhitungan menampilkan perolehan akhir dari nilai - nilai peserta seleksi yang sudah diakumulasikan.

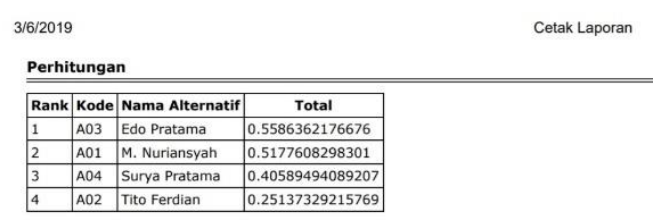

Gambar 8. Laporan Hasil Perhitugan

Form ini bertujuan untuk menampilkan laporan dari hasil seleksi atlet taekwondo yang telah dilakukan perhitungan berdasarkan penilaian menggunakan metode TOPSIS. Urutan pehitungan ditampilkan berdasarkan ranking tertinggi hingga terendah.

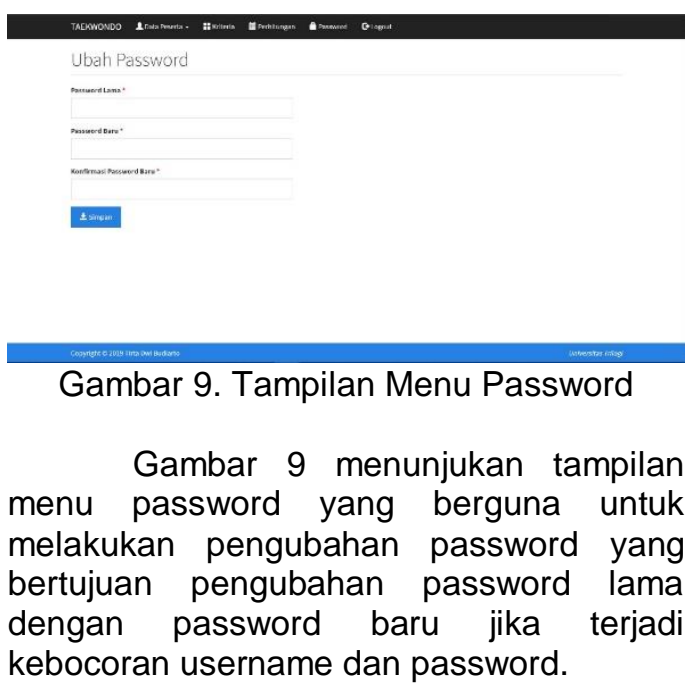

\section{Kesimpulan}

Memberikan Berdasarkan hasil perancangan aplikasi seleksi atlet taekwondo dengan menerapkan metode TOPSIS untuk mendukung keputusan dapat ditarik kesimpulan sebagai berikut:

1. Aplikasi yang dirancang mampu mengelola inputan data peserta seleksi, data kriteria, serta nilai dari masing masing kriteria yang selanjutnya dilakukan perhitungan terhadap proses penilaian akhir dari peserta seleksi atlet taekwondo. Hal ini memberikan kemudahan dalam melakukan perhitungan dalam pemilihan atlet terbaik.

2. Penerapan Metode TOPSIS memberikan hasil yang maksimal dalam melakukan pengambilan 
keputusan sesuai dengan bobot dari kriteria yang ditentukan.

\section{Referensi}

Ma'ruf. (2016). Pemilihan Supplier Menggunakan Metode Topsis Pada Perusahaan Furniture Development Of Decision Support System Supplier Selection Using Topsis Furniture Company Ma'ruf Abstrak Pendahuluan, 287-304.

Muzakkir, I. (2017). Penerapan metode topsis untuk sistem pendukung keputusan penentuan keluarga miskin pada desa panca karsa ii, 9, 274-281.

Riandari, F., Hasugian, P. M., Taufik, I., Informatika, T., \& Utara, S. (2017). SISTEM PENDUKUNG KEPUTUSAN MENGGUNAKAN METOD E TOPSIS, 2(1).

Widiyanto, Tri Ardy; Erliana, Y. (2016). KARYAWAN TERBAIK PADA PT. TEMBAGA MULIA. 